\title{
Feasibility Analysis of Levying Education Tax Based on Property in China_-Gray System Prediction Model Using Shandong Province Data
}

\author{
Xiao Feng ${ }^{1}, \mathrm{Ke} \mathrm{Gao}^{2,3}$ \\ ${ }^{1}$ School of Government, Central University of Finance and Economics, Beijing, P. R. China \\ ${ }^{2}$ PBC School of Finance, Tsinghua University, Beijing, P. R. China \\ ${ }^{3}$ Development Research Center of Shandong Provincial People's Government, Jinan, P. R. China \\ Email address: \\ fengxiao@jn.gov.cn (Xiao Feng),gkfly@126.com (Ke Gao) \\ To cite this article: \\ Xiao Feng, Ke Gao. Feasibility Analysis of Levying Education Tax Based on Property in China_ _ Gray System Prediction Model Using \\ Shandong Province Data. Humanities and Social Sciences. Vol. 6, No. 5, 2018, pp. 173-181. doi: 10.11648/j.hss.20180605.15
}

Received: November 13, 2018; Accepted: December 3, 2018; Published: December 12, 2018

\begin{abstract}
Education is the cornerstone of a country's development and the mainstay of national competitiveness. A high-quality education system is not only the need for the construction of an innovative country, but also the foundation of the great rejuvenation of the Chinese nation. Since the 21 st century, the growth of China's fiscal education funds has accelerated year by year. In 2012, the goal of fiscal education funds accounting for 4\% of GDP was finally completed. However, this has not been able to meet the needs of the entire society for the explosive growth of education, far less than the world average of $4.4 \%$ over the same period. After the 19th National Congress of the Communist Party of China, China will make major changes in the field of education and taxation, China will give priority to the development of education, and expand the scope of property tax collection. With all those changes, China will have a chance to build its own education tax system. This paper proposes to construct a properties based education tax to replace the current education surcharge policy, and through the establishment of a gray model, analyze the data of Shandong Province in recent years, measure the expected income of education tax, and provide data supportfor the construction of education tax system.
\end{abstract}

Keywords: Fiscal Education Funding, Education Tax, Education Surcharge, Gray System

\section{Introduction}

Unlike most countries, China does not have an education tax. Instead, it is an administrative fee called "education surcharge", which is essentially an additional tax, based on the actual value-added tax and consumption tax paid by the taxpayer. Such rule began in April 1986, and experienced several modifications $[1,2]$. Although the rule has played a significant role in the development of national education and the financing the education system, it has also exposed many problems: (1) Regional differences, lots of undeveloped areas a lack of "education surcharge" [3]. (2) Misappropriation of funds, administrative fee is not equal to tax, in a report published in 2016 by Beijing Normal University, in poverty-stricken areas, public funds in education expenses are extremely small, education fees are not subject to education appropriation. [4] (3) Some regional normative documents confused with legal provisions [5].

Therefore, under such a background, China should levy an education tax, and a reasonable taxation of education tax can effectively increase the source of financial education funding and promote the long-term development of education.

The call for education tax has a long history [6], but the state has not yet levied an education tax. The main reason is that if the education tax is actually calculated for the property, it will affect the local fiscal revenue, especially the local fiscal education fund compare with the current education surcharge policy. This paper will taking Shandong Province as an example, uses Gray prediction model and regression model to measure the impact of education tax on local fiscal education 
fund income.

\section{The Choice of Tax Base for Education Tax}

The definition of the tax base is the basis for calculating the taxable amount determined by the tax law, The basis of taxation is the most basic aspect of a tax system, because it not only affects the difference of taxation objects, but also affects the scope of taxpayers, and the bearers of the final tax burden. At present, the "education surcharge" in China is an additional tax based on the commodity turnover tax. Therefore, the construction of a new education tax, there are three different options in the choice of tax base. First, the existing education additional policy will remain unchanged, and the education tax will be levied on the basis of value-added tax and consumption tax. Second, the education tax will be levied on the basis of personal incomes. Thirdly, the education tax is levied on the basis of the property tax. All choices will be analyzed separately as below:

(1) The amount of VAT and consumption tax as tax base

This option can directly carry out the reform of "fee-to-tax reform", However, under the current tax system, the program still has big problems. According to the data released by the National Bureau of Statistics, in the period of 2012-2015, with the reduction of small and micro enterprises tax cuts, and structural tax cuts, 641.2 billion Yuan has been cut [7], according to the current The levy standard, which will lead to a reduction of about 32.06 billion Yuan in education. What is worse, the tax base is too narrow and vulnerable to economic fluctuations, Value-added tax and consumption tax are basically a barometer of regional economic development. As an additional tax, education surcharge will inevitably be subject to large fluctuations. Therefore, in the long run, direct it is not feasible to levy an education tax on the basis of VAT and consumption tax.

(2) Personal incomes as tax base

This option has precedents in many western developed countries. Take US as an example, there is no VAT in the United States. Income tax is one of the most important taxes in the country, Its income plays an important role in the government's fiscal revenue. Therefore, as a tax base, it can fully guarantee the education tax and meet the education needs for funding. In contrast, China's personal income tax has undergone seven major revisions since its inception in 1980, the most recent of which was June 19, 2018, which was reviewed and approved at the Fifth Session of the Standing Committee of the 13th National People's Congress, effective in October $1^{\text {st }} 2018$, Personal income tax is the fourth largest tax in China. As can be seen from the figure, the proportion of personal income tax in China's total tax revenue has been fluctuating around $5 \%-7 \%$.

In 2008 , the total amount of state tax revenue in the United States in 2008 was 2,524.3 billion US dollars, of which personal income tax income was $1,450.1$ billion US dollars, accounting for nearly $60 \%$ of the total federal government tax revenue [8], so, both in terms of total amount and proportion. China's Personal income tax is not comparable to other developed countries. If this option will be applied, the shortage of education funds will be more severe.

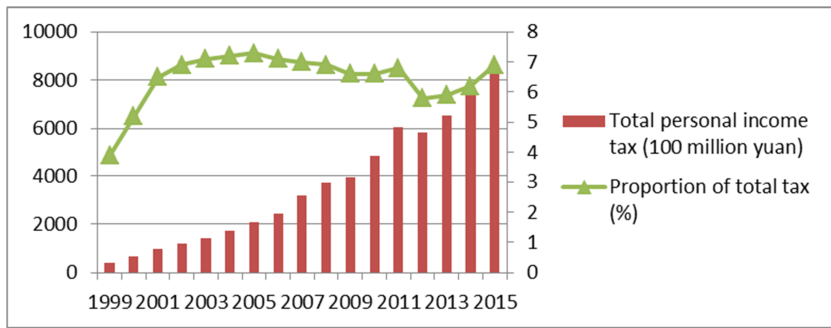

Figure 1. China's personal income tax overview from 1999 to $2015^{I}$.

(3) Properties as tax base

In solving the problem of local government education funding, many western developed countries have adopted property taxes ${ }^{2}$ to support local education, especially compulsory education. Taking property as the tax base and levying education tax can effectively guarantee the stability of the supply of education funds. If the education tax is taxed at the assessed price of the property, the tax base and tax rate can be adjusted by the local government according to the local conditions, and the taxation of the real estate is stable, and the tax revenue will not fluctuate with the local economic changes.

In 2011, China launched a property tax pilot in Shanghai and Chongqing. At the 19th Party Congress held in 2018, the central government clearly proposed to introduce real estate tax in recent years [9]. In China real estate is the most valuable part of person or groups' properties, and the income of real estate tax almost equal to the property tax in China.

Therefore, in the current context of the new era, the most suitable for the education tax base of China should be property, which can guarantee the sustainable supply of education funds without economic fluctuations and changes in the external environment. The actual situation of each place is levied at its discretion, and it does not increase the overall tax burden of the society. It is the most ideal choice.

1Source: National Bureau of Statistics of China, National Data Website 2To explore property tax here, we need to specify China's national conditions and national body. The nature of land in China is state-owned. Urban land use tax is essentially a resource tax, not a property tax. This is very different from other countries. China's property tax is only three kinds of real estate tax, deed tax, vehicle and vessel tax. In order to be in line with international standards and improve the fit of the education tax model, we also classify the urban land use tax as property tax. 


\section{Forecast of the Impact of Education Tax on Education Funds Income (A Case of Shandong Province)}

\subsection{Basic Assumption}

(1) Education tax levy time setting.

Data on education fees and other related education taxes and fees in China can be obtained from the "China Education Funding Statistical Yearbook" published by the Ministry of Education every year from 2012 to 2016 , and can be used to make future trends through regression calculations. This article assumes that from January 1, 2013, the education tax based on property as described above will be introduced to replace the original education surcharge. In view of the fact that the main indicators set in the "National Medium and Long-Term Education Reform and Development Plan (2010-2020)" and the "Relevant Development Plan of Shandong Province" in are all in 2020, the education tax measurement end point is 2020 .

(2) Definition of property scope.

According to the existing research significance and the availability of data, taxable property will be fixed in the commercial housing of urban residential houses.

(3) Basis for taxation of education tax.

Since China's existing property appraisal system has not yet been established, from the experience of property tax in Shanghai and Chongqing, the real estate property evaluation price are deducted as the basis, and adopted the average sales price of new residential commercial housing as the tax basis for property tax, the area of taxable property. Since both places have a certain amount of exemption and fee deduction, and the taxable properties of the two places are basically all directed to the incremental housing (except for Chongqing for high-end stock housing), the sale of commercial housing will be taken during the implementation of the real estate tax in the above two places. The ratio of the area to the gross floor area of the commercial residential building is calculated as the occupancy rate of the residential commercial housing area (Shanghai is calculated based on the period cost deduction standard and $70 \%$ of the commercial housing sales area is included in the total sales area, the same below). The actual education tax calculation basis after the method above should be greater than the assumed value [10].

(4) Education tax rate.

The taxation of education tax should not increase the overall tax burden of the whole society. The current real estate tax in China has not yet been implemented. The real estate tax in Shanghai and Chongqing is set at $0.4 \%-1.2 \%$ during the pilot process. This article assume that the education tax rate should be $1 \%$ of the tax property price.

(5) Actual collection rate.

With the gradual improvement of China's real estate market supervision and the improvement of informatization, basically all taxable property has formed electronic archives through relevant systems, and the loopholes in the collection and management have been gradually blocked, and this paper is the ability to earn income from education taxation. The calculation is based on the actual rate of $100 \%$.
(6) Discount rate.

In this paper, the discount rate is calculated by reference to the national financial institution's loan interest rate of five years or more. According to the relevant data released by the central bank, the financial institution's five-year and above loan interest rate is $6.55 \%$, so the discount rate of this paper is set at $6.55 \%$.

(7) Tax incentives.

For the time being, this article does not consider the non-tax and tax incentives for some taxable property, and does not consider the central government's transfer payments to provincial and sub-national governments.

(8) Land transferfee data is not included in the calculation.

\subsection{Variable Definition}

The model related variables are defined as follows:

$N-$ The $\mathrm{n}^{\text {th }}$ year

$X-$ City per capita housing area $\left(\mathrm{m}^{2}\right)$

$b \longrightarrow$ Residential rate of residential commercial housing area $(\%)$

$Q-$ The number of permanent residents in urban areas (10,000 people)

$P$-Average selling price of residential commercial housing (Yuan $/ \mathrm{m}^{2}$ )

$T_{a}$ Education surcharge income (10,000 Yuan)

$T_{e} \_$Education Tax income (10,000 Yuan)

$t_{b}-$ Education tax's tax basis

$t_{e}$-Education tax's tax rate

$E$ - Actualcollection rate

$d-$ Discount rate

$Y$ - Local financial education funding income

All the data used in this model are all from the China Education Funding Statistical Yearbook, Shandong Statistical Yearbook, and China Family Panel Studies (CFPS).

\subsection{Forecasting Process}

According to the basic formula of taxation, namely "tax revenue $=$ tax basis $\times$ tax rate $\times$ actual rate of collection", the formula for calculating the education tax income is:

$$
T_{e}=t_{b} \times t_{e} \times E=X \times Q \times P \times t_{e} \times E \times b
$$

According to the "Shandong Province Urban System Plan (2011-2030)" issued by the Shandong Provincial Department of Housing and Urban-Rural Development in 2017, "the resident population will be about 103 million by 2020, of which the urban population is about 67 million, and the resident population. The urbanization rate is about $65 \%$; the urbanization rate of the registered population is about 55\%." In addition, the Shanghai Statistical Yearbook 2012-2017 and the Chongqing Statistical Yearbook 2012-2017, after the pilot of the property tax in the above two places, the two places The total area of new commercial housing transactions was 341.589 million square meters. The total area of residential commercial housing in 2016 was 18,653,388 square meters, so this model $Q=6700, E=100 \%, b=18.33 \%$. The data of other variables need further Estimate. 


\subsubsection{Estimation of the Average Price of Commercial Housing Sales in 2020}

China stipulates that the land use period is 70 years. The majority of the residential property houses in China are the same as the 70 years. If the education tax is levied on the above-mentioned property, it will inevitably lead to changes in house prices. Let us assume that education is levied. After the after-tax housing price is $P_{n}^{\prime}$, the tax system maintains the current housing priceis $P_{n}$, then the following relationship will exist between them:

$$
P_{n}=\left[1+\left(1+\frac{1}{1+d}+\frac{1}{(1+d)^{2}}+\ldots+\frac{1}{(1+d)^{69}}\right) \times\left(t_{e}\right)\right] P_{n}^{\prime}
$$

Among them, the discount rate $d=6.55 \%$, the education tax rate $t_{e}=1 \%$, and substitute them into equation (3-2) it can be obtained:

$$
P_{n}^{\prime}=0.8601 P_{n}
$$

After obtaining the quantitative relationship between the average price of houses before and after taxation, it is necessary to predict the change trend of the average house price in Shandong Province. Here, the OLS regression model is established, and the data from 2007-2016 is used as the sample value to make data predictions. From the Shandong Statistical Yearbook (2008-2017) the above sample values can be obtained as shown in the following table:

Table 1. Average price of residential commercial housing in Shandong Province from 2007 to $2016^{3}$.

\begin{tabular}{llll}
\hline Year & $\begin{array}{l}\text { Residential commercial housing sales (10,000 } \\
\text { Yuan) }\end{array}$ & Total sales area of commercial housing $\left(\mathbf{m}^{2}\right)$ & $\begin{array}{l}\text { Average price of residential } \\
\text { commercial housing (Yuan) }\end{array}$ \\
\hline 2016 & 60705448 & 105985784 & 5727.70 \\
2015 & 45107586 & 85268531 & 5290.06 \\
2014 & 40094832 & 79724856 & 5029.15 \\
2013 & 44610664 & 93002852 & 4796.70 \\
2012 & 35295110 & 77458724 & 4556.63 \\
2011 & 37576321 & 87411567 & 4298.78 \\
2010 & 32180220 & 84482551 & 3809.10 \\
2009 & 22039733 & 65161728 & 3382.31 \\
2008 & 14369329 & 50394023 & 2851.40 \\
2007 & 13184361 & 47096611 & 2799.43 \\
\hline
\end{tabular}

Then use Eviews to establish a one-dimensional OLS linear regression model. Since 2007 is the first year, so that 2007 is $N=1$, 2008 is $N=2$, and so on, and the linear regression of the constructed OLS $P_{n}=\alpha N+\beta$, and the following results are obtained:

Table 2. Parameters of regression model of average price of commercial housing in Shandong Province.

\begin{tabular}{llll}
\hline Variable & Coefficient & Std. Error & t-Statistic \\
\hline C & 2424.796 & 93.02425 & 26.06628 \\
X & 332.6055 & 14.99222 & 22.18521 \\
\hline
\end{tabular}

\begin{tabular}{llll}
\hline R-squared & 0.984006 & Mean dependent var & 4254.126 \\
Adjusted R-squared & 0.982007 & S.D. dependent var & 1015.164 \\
S.E. of regression & 136.1736 & Akaike info criterion & 12.84259 \\
Sum squared resid & 148345.9 & Schwarz criterion & 12.90311 \\
Log likelihood & -62.21297 & Hannan-Quinn criter. & 12.77621 \\
F-statistic & 492.1836 & Durbin-Watson stat & 1.294130 \\
Prob (F-statistic) & 0.000000 & & \\
\hline
\end{tabular}




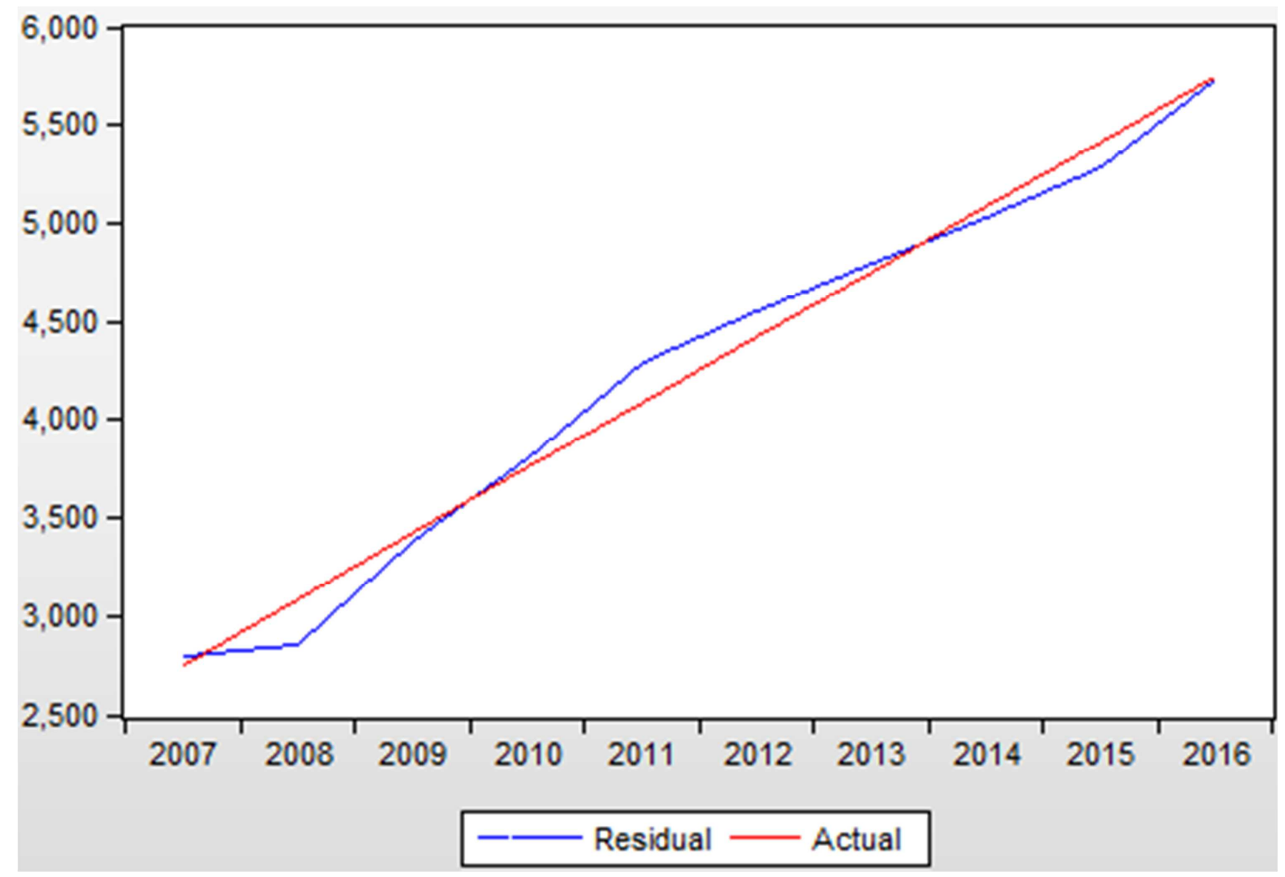

Figure 2. Average price of commercial housing in Shandong Province from 2007 to 2016.

$$
P_{n}=2424.80+332.61 \times N
$$

Bringing $N=14$ to bring into (4-4), it is known that before the introduction of education tax in Shandong Province, the average price of commercial housing is $P_{14}=7081.34$ Yuan $/ \mathrm{m}^{2}$, and bring $P_{14}=7081.34$ into (3-3), Shandong Province is in the process of levying After the education tax based on property, the average price of commercial housing is $P_{14}^{\prime}=6963.87 \mathrm{Yuan} / \mathrm{m}^{2}$.

\subsubsection{Estimation of the Per Capita Residential Area of \\ Urban Areas in 2020}

The per capita residential area of the town belongs to the gray system. It will be needed to use the gray system method to predict the per capita residential area of the future towns in Shandong Province. The gray system method was born in the cybernetics of information science, and then gradually applied to the field of sociology and economics. This method is most effective for the study of the "small sample" and "less information" uncertainty systems [11]. Therefore, in the process of predicting and analyzing the gray model of the GM $(1,1)$ sample of the 2007-2016 sample of the per capita residential area of Shandong Province. The steps are as follows:

Step1. Constructing the general form of GM $(1,1)$

The general form of $\operatorname{GM}(1,1)$ is to set $X^{(0)}=\left\{X^{(0)}(i), i=1,2, \ldots, n\right\} \quad$ a non-negative monotonic original data column with variables as a prediction object. In this model, $X^{(0)}$ is the per capita residential area of urban areas in Shandong Province. The resulting gray prediction model is as follows: First, the accumulation is performed once. The operation1-AGO (Accumulated Generating Operator) generates an accumulation sequence:

$$
\begin{gathered}
X^{(1)}=\left\{X^{(1)}(k), k=1,2, \ldots, n\right\} \\
X^{(1)}(k)=\sum_{i=1}^{k} X^{(0)}(i)=X^{(1)}(k-1)+X^{(0)}(k)
\end{gathered}
$$

The raw data $X^{(0)}$ can be obtained from the Shandong Statistical Yearbook (2008-2017). The per capita residential

\begin{tabular}{|c|c|c|c|c|c|c|c|c|c|c|}
\hline Year & 2007 & 2008 & 2009 & 2010 & 2011 & 2012 & 2013 & 2014 & 2015 & 2016 \\
\hline Per capita housing area $\left(\mathrm{m}^{2} /\right.$ person $)$ & 29.8 & 31.33 & 31.80 & 32.09 & 33.18 & 33.44 & 37.93 & 38.72 & 38.52 & 39.60 \\
\hline
\end{tabular}
area in Shandong Province is shown in the following table:

Table 3. 2007-2016 Shandong Province Per Capita Housing Area ${ }^{4}$. 
In this paper $\hat{X}^{(0)}=\{29.8,31.33,31.80,32.09,33.18$, $33.44,37.93,38.72,38.52,39.60\}$, after the formation of monotonic data columns, eliminating data fluctuations, substituting (3-5) for accumulating operations 1-AGO, generating The new sequence is $\hat{X}^{(1)}=\{29.8,61.13,92.93$, $125.02,158.20,191.64,229.57,268.29,306.81,346.41\}$. establish the gray model whitening differential equation for $\hat{X}^{(1)}$ :

$$
\frac{\mathrm{d} X^{(1)}}{\mathrm{d} t}+a X^{(1)}=u
$$

Equation (3-6) is the general form model of $\operatorname{GM}(1,1)$.

The special solution of the equation (3-6) in the discrete response can be solved by the differential equation, as follows:

$$
\hat{X}^{(1)}(k+1)=\left(X^{(0)}(1)-\frac{u}{a}\right) e^{-a k}+\frac{u}{a}
$$

Where $\boldsymbol{k}$ is a time series, the data in this article are all in years, so $\boldsymbol{k}$ take as year.

Step2. Identification algorithm to solve parameters

The parameter sequence is $\hat{a}$, where $\hat{a}=[a, u]^{T}, \hat{a}$ 's solution is as follows:

$$
\hat{a}=\left(B^{T} B\right)^{-1} B^{T} Y_{n}
$$

Where $B$ is the data matrix, $Y_{n}$ is the data column, the expression is as follows:

$$
\begin{gathered}
B=\left[\begin{array}{cc}
-\frac{1}{2}\left(X^{(1)}(1)+X^{(1)}(2)\right) & \\
-\frac{1}{2}\left(X^{(1)}(2)+X^{(1)}(3)\right) & 1 \\
\cdots & 1 \\
-\frac{1}{2}\left(X^{(1)}(n-1)+X^{(1)}(n)\right) & \\
Y & =\left(X^{(0)}(2), X^{(0)}(3), \cdots, X^{(0)}(n)\right)^{T}
\end{array}\right.
\end{gathered}
$$

Using MATLAB software, through matrix operation, $\mathrm{a}=-0.0339 \mathrm{u}=29.0753$, where $\mathrm{a}$ is called the development coefficient. In the gray model, the development coefficient a has a direct impact on the accuracy of the $\operatorname{GM}(1,1)$ model. It is generally considered When $-\mathrm{a} \leq 0.3$, the prediction accuracy of the first 5 steps of the GM $(1,1)$ model is above $97 \%$ [12]. In this paper, the number of steps to be predicted is 4 steps (2017-2020), so the GM $(1,1)$ The model has economic significance, so the gray prediction model GM $(1,1)$ in this paper is:

$$
\frac{\mathrm{d} X^{(1)}}{\mathrm{d} t}-0.0339 X^{(1)}=29.0753
$$

The special solution under discrete response is:

$$
\hat{X}^{(1)}(k+1)=\left(X^{(0)}(1)+\frac{29.0753}{0.0339}\right) e^{0.0339 k}+\frac{29.0753}{0.0339}
$$

Bring the time response function, it can be figured:

$$
\hat{X}^{(1)}=\{29.80,60.40,92.05,124.80,158.67,193.71,229.96,267.46,306.24,346.37\}
$$

Step 3. Restore predicted values $X$

The value $\hat{X}^{(1)}$ is generated after $1-\mathrm{AGO}$, and if the original sequence is obtained, a subtraction is required. The specific method is as follows:

$$
\hat{X}^{(0)}(k)=\hat{X}^{(1)}(k)-\hat{X}^{(1)}(k-1)
$$

Bring $\hat{X}^{(1)}$ to equation (3-13)

$$
\hat{X}^{(0)}=\{29.80,30.60,31.65,32.74,33.87,35.04,36.25,37.50,38.79,40.12\}
$$

Step4. Test of gray prediction model GM $(1,1)$

To measure the accuracy of the gray prediction model, it is necessary to pass three parameters, namely "relative error", "mean square error ratio" and "small error probability". First, the relative error test is performed. The relative error needs to calculate the residual sequence $\varepsilon^{0}$ and the relative error sequence $\Delta_{k}$, where

$$
\varepsilon^{(0)}=\{\varepsilon(1), \varepsilon(2), \cdots, \varepsilon(n)\}
$$

$$
\begin{gathered}
=\left\{X^{(0)}(1)-\hat{X}^{(0)}(1), X^{(0)}(2)-\hat{X}^{(0)}(2), \ldots, X^{(0)}(n)-\hat{X}^{(0)}(n)\right\} \\
\Delta_{k}=\left\{\left|\frac{\varepsilon(1)}{X^{(0)}(1)}\right|,\left|\frac{\varepsilon(2)}{X^{(0)}(2)}\right|, \ldots,\left|\frac{\varepsilon(n)}{X^{(0)}(n)}\right|\right\}
\end{gathered}
$$

The model relative error test value can be obtained by bringing the predicted value and the initial value in the GM (1, 1) model, as shown in the following table: 
Table 4. GM $(1,1)$ relative error checklist.

\begin{tabular}{lccccc}
\hline No. (n) & Year & $X^{(0)}$ & $\hat{X}^{(0)}$ & $\varepsilon^{(0)}$ & $\Delta_{k}$ \\
\hline 1 & 2007 & 29.80 & 29.80 & 0.00 & $0.000 \%$ \\
2 & 2008 & 31.33 & 30.60 & 0.73 & $2.330 \%$ \\
3 & 2009 & 31.80 & 31.65 & 0.15 & $0.458 \%$ \\
4 & 2010 & 32.09 & 32.74 & -0.65 & $2.041 \%$ \\
5 & 2011 & 33.18 & 33.87 & -0.69 & $2.089 \%$ \\
6 & 2012 & 33.44 & 35.04 & -1.60 & $4.785 \%$ \\
7 & 2013 & 37.93 & 36.25 & 1.68 & $4.436 \%$ \\
8 & 2014 & 38.72 & 37.50 & 1.22 & $3.160 \%$ \\
9 & 2015 & 38.52 & 38.79 & -0.27 & $0.696 \%$ \\
10 & 2016 & 39.60 & 40.12 & -0.52 & $1.325 \%$ \\
\hline
\end{tabular}

The average relative error of the GM $(1,1)$ model is $\bar{\Delta}=$ $\frac{1}{n} \sum_{k=1}^{n} \Delta_{k}=0.021 \leq 0.05$, and $\Delta_{n}=0.0013 \leq 0.05$, so the model is a relative error qualified model.

Secondly, the mean square error ratio test should be carried out, the mean square error ratio is $c=\frac{s_{2}}{s_{1}}$, where $s_{1}$ is the mean square error of $X^{(0)}, s_{2}$ is the mean square error of $\mathcal{E}^{(0)}$, $s_{1}=\sqrt{\frac{\sum\left(X^{(0)}(k)-\overline{X^{(0)}}\right)^{2}}{n}}, \quad s_{2}=\sqrt{\frac{\sum\left(\varepsilon^{(0)}(k)-\overline{\varepsilon^{(0)}}\right)^{2}}{n}}$, After solving, $s_{1}=13.2942, s_{2}=0.966, c=0.0727 \leq 0.35$, In the actual prediction process, the mean square error ratio is less than 0.35 , and the model can be considered the mean square error ratio test can be passed. Therefore, the model is the mean square error ratio test qualified model.

Finally, a small error probability test, small error probability $p=p\left\{\left|\Delta^{(0)}(k)-\overline{\Delta^{(0)}}\right|<0.6745 s_{1}\right\}$, after solving $p=1>0.9$, the GM $(1,1)$ model is highly accurate and can be used for actual prediction. Then, using the formula (3-12) (3-13) to predict the next four steps, the per capita residential area in Shandong Province from 2017 to 2020 is 41.51, 42.94, 44.42, $45.95 \mathrm{~m}^{2} /$ person.

\subsection{Forecast Result}

Before the new education tax, China's local government education funds over-reliance on central transfer payments. From the perspective of sources of funds, China's education funds still mainly come from financial allocations. In the case of limited education funds, China has long faced financial education at all levels. The problem of uncoordinated allocation of funds has led to inefficient use of funds and low quality of education. In the countries with developed education and perfect systems, the financial expenditure structure of education at all levels from low to high is basically a "pyramid" type [13]. Education at all levels is relatively balanced, and the gap in financial education for students is not obvious. In the context of the current education additional policy, taking Shandong Province as an example, from 2010 to 2016, the financial education funds and education-added income of Shandong Province are shown in the following table:

Table 5. Financial education funds and education surcharges in Shandong Province 5 .

\begin{tabular}{llll}
\hline Year & State financial educational funds (10,000Yuan) & education surcharge (10,000Yuan) & Percentage of total funding (\%) \\
\hline 2016 & 19362978.8 & 1185106.9 & 6.12 \\
2015 & 17945269.5 & 1045845.2 & 5.83 \\
2014 & 16325282.9 & 998573.6 & 6.12 \\
2013 & 15473322.3 & 964146.7 & 6.23 \\
2012 & 14538933.2 & 874192.3 & 6.01 \\
2011 & 11811966.2 & 761654.2 & 6.45 \\
2010 & 8391237.2 & 555967.1 & 6.63 \\
\hline
\end{tabular}

Education surcharge is one of the main sources of local education funds, and its proportion has been at a low level. This shows that under the current system, China's education funds, especially local fiscal education funds, lack a stable source, once the state education finance The transfer payments have fluctuated, and local governments, especially the county-level governments, will be greatly affected. In addition, the changes in education fees caused by local economic fluctuations will have a huge impact on the quality of education.

If a new education tax is introduced to replace the previous education surcharge, in addition to enriching the source of education funding and providing sustainable protection for the local government education funding, it can also improve the current tax system for the lack of taxation of property retention. It can effectively curb the current phenomenon of "choosing schools by housing" in the compulsory education link and effectively promote the rational distribution of educational resources. After the new education tax is levied, compare the past education surcharges with the new education tax revenues. Result are as follows:

Table 6. Comparison of education surcharge and education tax.

\begin{tabular}{|c|c|c|c|c|c|}
\hline Year & $\begin{array}{l}\text { Education surcharge } \\
(10,000 \text { Yuan) }\end{array}$ & $\begin{array}{l}\text { Education Tax } \\
(10,000 \text { Yuan })\end{array}$ & $\begin{array}{l}\text { State financial educational } \\
\text { funds }(\mathbf{1 0 , 0 0 0 Y u a n})\end{array}$ & $\begin{array}{l}\text { Education surcharge/State } \\
\text { financial educational funds (\%) }\end{array}$ & $\begin{array}{l}\text { Education Tax/State financial } \\
\text { educational funds }(\%)\end{array}$ \\
\hline 2013 & 964146.70 & 1619241.14 & 15473322.30 & 6.23 & 10.46 \\
\hline
\end{tabular}




\begin{tabular}{llllll}
\hline Year & $\begin{array}{l}\text { Education surcharge } \\
(\mathbf{1 0 , 0 0 0 Y u a n )}\end{array}$ & $\begin{array}{l}\text { Education Tax } \\
(\mathbf{1 0 , 0 0 0 Y u a n )})\end{array}$ & $\begin{array}{l}\text { State financial educational } \\
\text { funds (10,000Yuan) }\end{array}$ & $\begin{array}{l}\text { Education surcharge/State } \\
\text { financial educational funds (\%) }\end{array}$ & $\begin{array}{l}\text { Education Tax/State financial } \\
\text { educational funds (\%) }\end{array}$ \\
\hline 2014 & 998573.60 & 1773093.72 & 16325282.90 & 6.12 & 10.86 \\
2015 & 1045845.20 & 1898075.47 & 17945269.50 & 5.83 & 10.58 \\
2016 & 1185106.90 & 2169745.59 & 19362978.80 & 6.12 & 11.21 \\
2017 & 1280809.79 & 2466295.45 & 21545310.18 & 5.94 & 11.45 \\
2018 & 1372959.17 & 2751603.36 & 23222745.22 & 5.91 & 11.85 \\
2019 & 1465108.55 & 3060822.70 & 24900180.26 & 5.88 & 12.29 \\
2020 & 1557257.93 & 3437060.51 & 26577615.30 & 5.86 & 12.93 \\
\hline
\end{tabular}

Therefore, the basic conclusion can be drawn that by levying the education tax based on property as a tax, it can completely replace China's current education surcharge policy and occupy a very important position in the local fiscal education fund income.

\section{Conclusion}

With the development of the national education industry, the demand for education funds is increasing day by day. How to solve the source of education funds and provide stable and sustainable supply for education has become an urgent problem to be solved in today's policy field. This paper uses mathematical model reasoning to the current feasibility of using education as a tax-based education tax has been analyzed. The results show that the education tax based on property can completely replace the current education surcharge policy, and can establish a tax collection and management system with complete education tax. Achieve a stable supply of education funds.

Therefore, in view of the current educational additional mechanism, reference is made to the foreign education tax collection and management model. It should be carried out the construction of education tax system in 2 steps to ensure the steady growth of education financial input.

\subsection{Constructing an Education Tax Based on Property}

As a kind of tax base, property is a kind of typical benefit tax, and it is also a tax for the property preservation link. At present, the taxation of property retention in China is too low, and the education tax levied on this tax base can guarantee adequate tax sources and tax stability [14]. At the same time, the education tax on property is essentially a direct tax. Direct tax has a unique advantage in the collection and management. On the one hand, taxpayers are not easy to evade taxes and evade taxes, and with the gradual improvement of China's real estate registration system, the real estate tax is docked. With the introduction of policies, loopholes in tax source declarations have become increasingly popular. On the other hand, direct taxes can effectively avoid double taxation. Scientific calculations can effectively prevent fluctuations in social macroeconomics caused by changes in tax burdens more economical. In addition, the United States and other Western countries use property tax as the core tax, providing very substantial funds for the development of local and state-level education. In this regard, China should introduce real estate tax and supporting policies and regulations, such as property evaluation, digital transactions, withholding and payment methods and other provisions, docking education tax, effectively alleviating the problem of insufficient local education funds.

\subsection{Set Reasonable Education Tax Incentives}

Under the current policy background of China's overall structural tax reduction policy, education tax can also increase the income of education funds through tax incentives or tax reductions. The state has introduced a series of policies on the aspects of VAT and income tax, such as public welfare or welfare projects provided by the school logistics department for school teaching and research activities [15]. Costs can be deducted before tax, and related campus services such as school printing factories and school infrastructure departments are included in the tax exemption scope. After the education tax is levied, in addition to the above-mentioned preferential policies, for education tax, the education-related real estate land shall be exempted from the education tax. At the same time, in the education tax property collection link, a reasonable fee deduction standard shall be set, and the individual shall be, different with personal income tax, take family as the basic unit when the tax base is calculated. For those who are currently "choosing schools by housing" in the compulsory education, the houses' evaluation value should be much higher to levy more education tax, and promote the fair distribution of educational resources from the education tax. Finally, in the property gift link, a reasonable tax incentive clause should be set up to link with the personal income tax, encourage the public to donate the corresponding property to the education field, optimize the donation declaration procedures, expand the scope of donations, increase the tax reduction, inducing the benign distribution of social property and the rational flow of educational resources.

\section{References}

[1] RenQiang. Suggestions on Perfecting China's Education Investment Tax Policy [J]. Taxation Research, 2010 (6).

[2] Zhang Wei, Deng Liping. China Has Unified the Urban Maintenance and Construction Tax and Education Surcharge Levied from Domestic, Foreign Invested Enterprises and Individuals [J]. Foreign Taxation, 2011 (01):61-62.

[3] Zhai Shuai. Feasibility Study of Expelling Education Tax [J]. Journal of Shanxi University of Finance and Economics, 2011, 33 (S4): 11-12.

[4] Si Shujie, Wang Wenjing, Li Xingzhou. China Education Poverty Reduction Report (2016)[M]. Beijing: Social Sciences Academic Press, 2016. 35-41. 
[5] Tang Wei. Legal Governance of Education Expenses [D]. Guangxi Normal University, 2015.

[6] Li Rui. The reform of education fees is the trend of the times [J]. Taxation, 2017 (01): 51-52.

[7] Li Lihui. Full implementation of the reform of replace business tax with value-added tax to increase profits and benefit the country [N]. People's Daily, 2016-04-26 (014).

[8] Vern Brimley, Jr. Financing Education: In a Climate of Change [M]. Beijing, China Renmin University Press, 2009; 107-129.

[9] Huang Zhilong. The Central Economic Work Conference released eight "Big Signals" [N]. China United Business News, 2017-12-25 (A04).

[10] Zhang Xiaoyue. Based on the experience of Chongqing and Shanghai real estate tax pilots to explore China's real estate tax reform [J]. Journal of Changchun University. 2014 (01).
[11] JiangShiquan, LiuSifeng, LiuZhongxia, Fang Zhigeng. A Generalized Gray Relational Analysis Model Based on General Gray Number [J]. Statistics \& Decision, 2018, 34 (18):74-78.

[12] Huang Hui. A New Gray Prediction Model for Dynamic Development Coefficient $a[J]$. Statistics \&Decision, 2016 (21): 19-21.

[13] HaoLinlin, Zhai Shuai. On the Tax Preferential System for Promoting the Development of Higher Education [M]. Beijing: Intellectual Property Publishing House, 2015.

[14] Zhang Youchang, Lu Liang. Research on Tax Preferential Policies of Colleges and Universities Based on Income Perspective [J]. Journal of Logistics Research, 2018 (10): $37-42$.

[15] Wang Dong, Jiang Yijie, Huang Bin. The Path Choice of China's Education Tax Management System Reform [J]. Taxation Research, 2017 (03):115-120. 